\title{
Anesthetic Management of a Patient with Goldenhar Syndrome Undergoing Emergency Caesarean Section: A Case Report
}

\author{
Subhash', Garima², Sweta1, ${ }^{1, *}$ \\ 1Department of Anesthesiology and Critical Care, LLRM, Meerut, Uttar Pradesh, INDIA. \\ ${ }^{2}$ Department of Anesthesiology and Critical Care, Medanta, Gurgaon, Haryana, INDIA.
}

\begin{abstract}
Goldenhar Syndrome (GS) is a relatively common developmental disorder characterized by craniofacial anomalies in association with vertebral, cardiac, renal, and central nervous system defects. A 24-year-old female patient reported to the Department of Obstetrics and Gynecology of with chief complaints of amenorrhea for 9 months and pain in abdomen. A provisional diagnosis of Goldenhar syndrome was made which was later confirmed by radiographic investigation Despite the presence of a difficult airway, awake fiber optic intubation was not possible as our patient refused to cooperate. We planned for general anesthesia as patient did not give consent for subarachnoid block. Patient was pre-oxygented with $100 \%$ oxygen for $3 \mathrm{~min}$. Induction of patient was done with injection propofol 100mg and cricoid pressure was applied after loss of consciousness. Injection succinylcoline $100 \mathrm{mg}$ was given intravenously and McGrath ${ }^{\mathrm{TM}}$ MAC video laryngoscope was used to intubate the patient. Anesthesia was maintained with nitrous oxide (60\%), oxygen (40\%). Atracurium was used as muscle relaxant during maintenance period. After extubation, patient was shifted to post anesthesia care unit for further observation and discharged later.
\end{abstract}

Key words: Goldenhar syndrome, Caesarean, Aesthetic management.
Article Information

Received: 21-05-2021

Revised : 01-07-2021

Accepted: 05-08-2021

Correspondence

Dr. Sweta

Assistant Professor, Department of Anesthesiology and Critical Care, LLRM, Meerut-250004, Uttar Pradesh, INDIA. Phone: $+91-8750933442$.

E-mail: swetaanae@gmail.com

\section{INTRODUCTION}

Goldenhar Syndrome (GS), also known as oculoauriculovertebral dysplasia or hemifacial microsomia has a wide range of clinical manifestations, including craniofacial, vertebral, cardiac, renal, and central nervous system anomalies. The typical presentation of GS includes epibulbar dermoids, microtia, mandibular hypoplasia, and vertebral anomalies. The causes for these developmental defects seem to be heterogeneous. GS is a condition with a prevalence ranging from 1:3,500 to $1: 7,000$ live births, and a male-female ratio of $3: 24$. Although most cases are sporadic, familial

\begin{tabular}{|l|c|}
\hline \multicolumn{2}{|c|}{ Access this article online } \\
\hline $\begin{array}{l}\text { Website: } \\
\text { www.jcramonline.com }\end{array}$ & Quick Response code \\
\hline DOI: & \\
10.5530/jcram.1.1.7 & \\
& \\
\hline
\end{tabular}

occurrences have been observed. This paper describes Anesthetic management of a patient with goldenhar syndrome undergoing emergency caesarean section.

\section{CASE REPORT}

A 24-year-old female patient reported to the department of Obstetrics and Gynecology of our medical college with the chief complaints of amenorrhea for 9 months and pain in abdomen for 1 day. Airway examination revealed limited mouth opening with inter-incisor gap less than $3 \mathrm{~cm}$ and mallampati grade III. Facial asymmetry was present with flattening of right side of face with loss of malar prominence along with presence of bilateral preauricular tags. [Figure 1]

Malocclusion was present with crowding of teeth and Macroglossia was also a prominent feature. [Figure 2] The neck was short with restricted neck movement.

The preoperative ophthalmic examination showed bilateral epibulbar dermoid in lateral fornix of eyes. [Figure 3] 


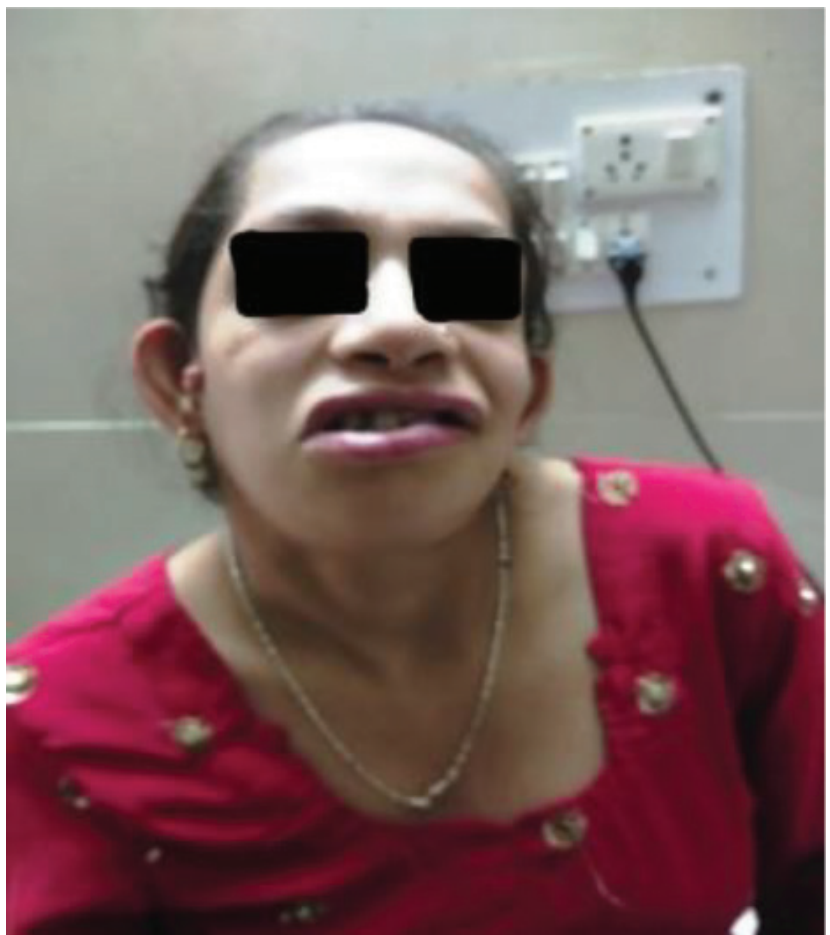

Figure 1: Facial asymmetry and preauricular tags.

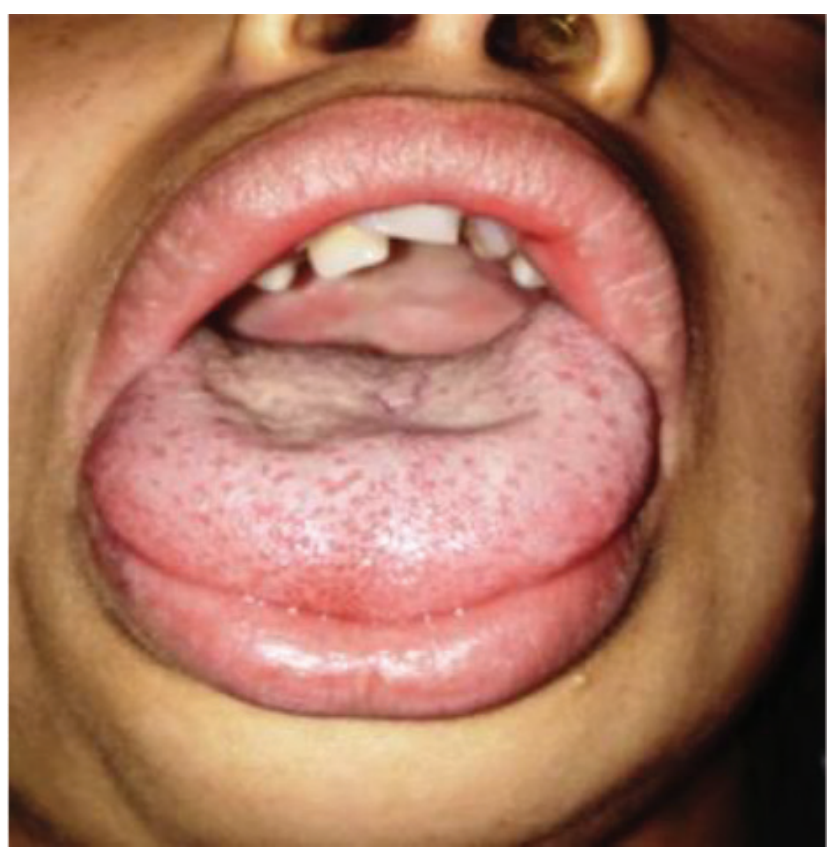

Figure 2: Macroglossia and malocclusion of teeth.

A provisional diagnosis of Goldenhar syndrome was made which was later confirmed by radiographic investigation (Computed Tomographic scan spine). Computed Tomographic scan revealed mild scoliosis at T5-T6 level. [Figure 4].

Hematological and biochemical investigations were unremarkable, along with normal 12-lead electrocar-

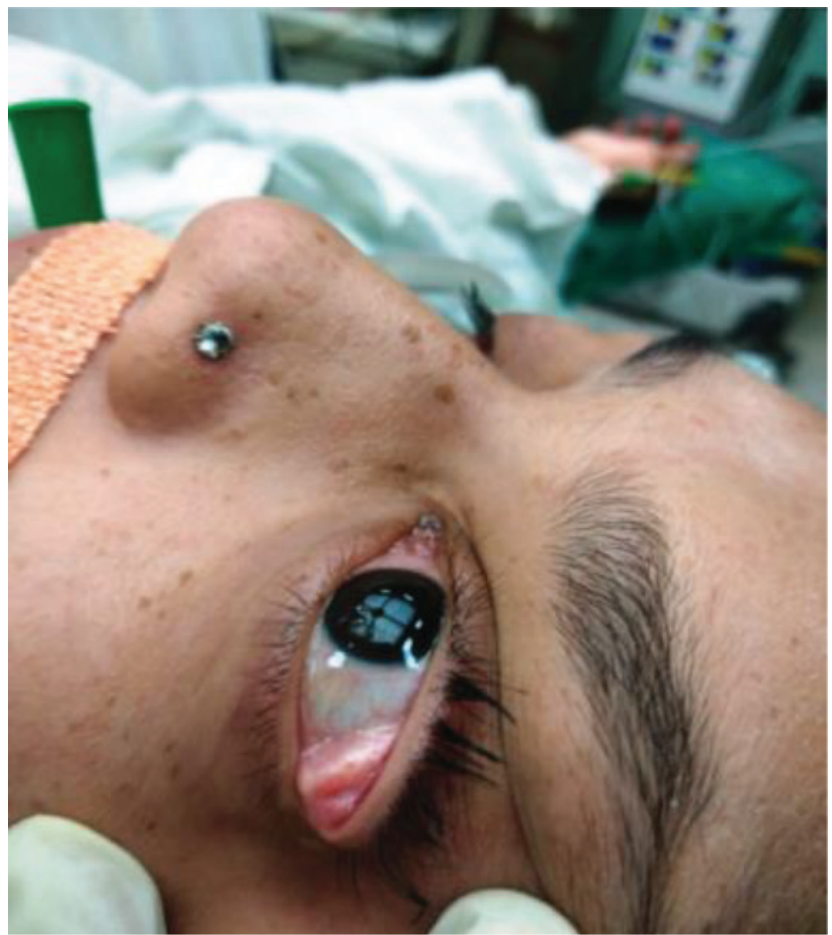

Figure 3: Epibulbar dermoid in lateral fornix.

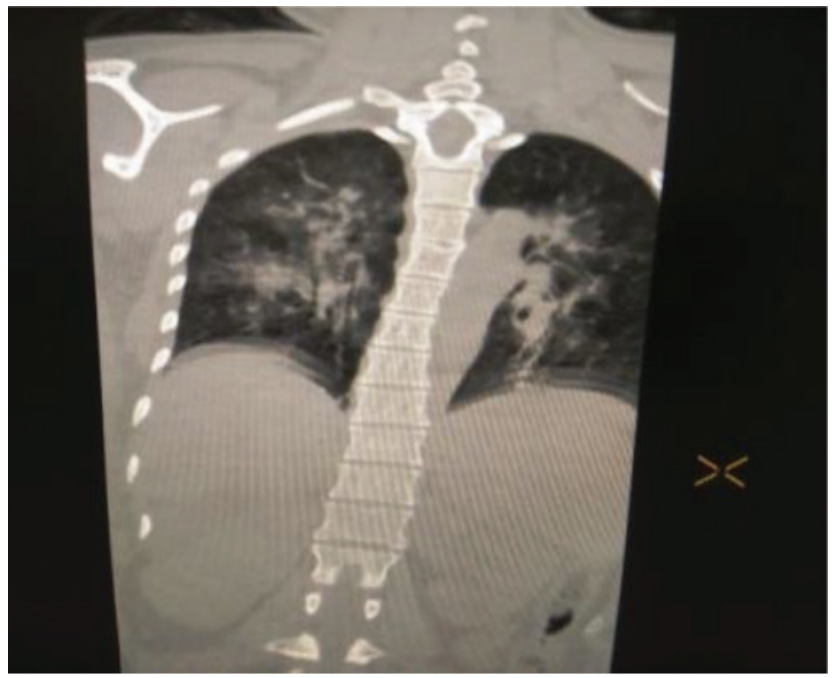

Figure 4: CT scan spine showed mild scoliosis at T5-T6 level.

diogram. 2D echocardiography was done after caesarean section which ruled out any cardiac anomaly.

Despite the presence of a difficult airway, awake fiber optic intubation was not possible as our patient refused to cooperate. We planned for general anesthesia as patient did not give consent for subarachnoid block. Informed written consent was taken from patient. The patient was nursed into Operation Theater in the left lateral position. On the operation table, multipara monitor was attached and baseline parameters, including 
pulse-rate $(90 / \mathrm{min})$, blood pressure (130/80), and peripheral oxygen saturation $(100 \%$ on room air) were recorded.

A $20 \mathrm{G}$ intra venous cannula was secured in nondominating forearm. Injection ranitidine $50 \mathrm{mg}$ and metoclopramide $10 \mathrm{mg}$ was given intravenously. Patient was preloaded with $10 \mathrm{ml} / \mathrm{kg}$ ringer lactate over $10 \mathrm{~min}$. Patient was preoxygented with $100 \%$ oxygen for $3 \mathrm{~min}$. Induction of patient was done with injection propofol $100 \mathrm{mg}$ and cricoid pressure was applied after loss of consciousness. Injection succinylcoline $100 \mathrm{mg}$ was given intravenously and $\mathrm{McGrath}{ }^{\mathrm{TM}} \mathrm{MAC}$ video laryngoscope was used to intubate the patient. Endotracheal tube $(7 \mathrm{~mm}$ with stylet in situ) was inserted after visualization of vocal cords. Cricoid pressure was released after confirmation of tube, and it was secured in position. Anesthesia was maintained with nitrous oxide $(60 \%)$, oxygen $(40 \%)$. Atracurium was used as muscle relaxant during maintenance period. After delivery of the baby, 5 IU of oxytocin was given slowly and $10 \mathrm{U} / \mathrm{hr}$ infusion started. Injection fentanyl 100 microgram and ondensetron $4 \mathrm{mg}$ was given intravenously. Intraoperative period was uneventful. At the end of surgical procedure, neuromuscular blockade was reversed with injection neostigmine $(2.5 \mathrm{mg})$ and glycopyrrolate $(0.4 \mathrm{mg})$. After extubation, patient was shifted to post anesthesia care unit for further observation and discharged later.

\section{DISCUSSION}

Goldenhar syndrome was first described by Dr. Maurice Goldenhar in 1952. The incidence has been reported to be 1:35,000-1:56,000 with a male to female ratio of $3: 2$ and it is more often presents in paediatric age group than adults. In this syndrome $90 \%$ of patients present with pre-auricular skin tags (90\%), 70 to $80 \%$ patients have vertebral anomalies and hemifacial microsomia, $30-60 \%$ patients present with microtia cardiac and central nervous system malformations, ocular anomalies and genitourinary malformations. ${ }^{1}$

Neuroaxial anesthesia is usually difficult or contraindicated due to spine malformations such as hemivertebrae, block vertebrae and spina bifida. As the child grows, airway management and administration of a general anesthesia becomes increasingly difficult due to restricted neck movements and airway anamolies. ${ }^{2}$

Various techniques such as Airtraq optical laryngoscope, awake fiberoptic intubation, Laryngeal mask airway have been described to manage the airway of patients with Goldenhar syndrome., ${ }^{3,4}$ Differential diagnosis of this syndrome includes Treacher-Collins syndrome and Townes Brocks syndrome, Mandibulofacial dysostosis and Miller Syndrome (postaxial acrofacial dysostosis). Treacher-Collins syndrome usually shows similar features with a bilateral presentation. TownesBrocks syndrome shows additional thumb anomalies, anal defects, and renal anomalies. ${ }^{5}$

\section{CONCLUSION}

The obstetric patient with Goldenhar syndrome presents a number of anesthetic challenges due to craniofacial deformities. A multidisciplinary approach is required for early diagnosis and successful management of airway.

\section{ACKNOWLEDGEMENT}

The author would like to thank all the author along with participants in the Study.

\section{CONFLICT OF INTEREST}

The authors declare no conflict of interest.

\section{REFERENCES}

1. Ashokan CS, Sreenivasan A, Saraswathy GK. Goldenhar syndrome review with case series. J Clin Diagn Res. 2014;8(4):ZD17-9. doi: 10.7860/ JCDR/2014/7926.4260, PMID 24959523.

2. Martelli H Jr., Miranda RT, Fernandes CM, Bonan PR, Paranaíba LM, Graner E, Coletta RD. Goldenhar syndrome: clinical features with orofacial emphasis. J Appl Oral Sci. 2010;18(6):646-9. doi: 10.1590/s167877572010000600019 , PMID 21308299.

3. Sasanuma H, Niwa Y, Shimada N, Machida M, Irei T, Hayashi K, Takeuchi M. Tracheal intubation using Airtraq optical laryngoscope in an adult patient with Goldenhar syndrome. Masui. 2013;62(7):867-9. PMID 23905414.

4. Hezelgrave NL, Srinivas K, Ahmad I, Mascarenhas L. Use of awake oral fibreoptic intubation (AFOI) for caesarian section in a woman with Goldenhar syndrome: Acase report. Eur J Obstet Gynecol Reprod Biol. 2011;159(2):479-80. doi: 10.1016/j.ejogrb.2011.08.004, PMID 21962463.

5. Gorlin RJ, Cohen MM, Levin LS. Syndromes of the head and neck. 4th ed. Oxford: Oxford University Press; 1990. p. 707-8.

Cite this Article : Subhash, Garima, Sweta. Anesthetic Management of a Patient with Goldenhar Syndrome Undergoing Emergency Caesarean Section: A Case Report. J. Clin. Res. Applied Med. 2021;1(1):29-31. 